\title{
Influence of Different Yeast Strains on Metabolism of Tryptophan and Indole-3-Acetic Acid During Fermentation
}

\author{
M. Mihaljević Žulj”, I. Tomaz, L. Maslov Bandić, I. Puhelek, A.M. Jagatić Korenika, A. Jeromel \\ Faculty of Agriculture, University of Zagreb, Svetošimunska 25, 10000 Zagreb, Croatia
}

Submitted for publication: May 2014

Accepted for publication: July 2015

Key words: Ammonium sulphate, indole-3-acetic acid, tryptophan, untypical ageing off-flavour (UTA), yeast strain, 2-aminoacetophenone

\begin{abstract}
The effect of supplementation of Riesling (Vitis vinifera L.) must with ammonium sulphate (AS) on tryptophan (Trp) and indole-3-acetic acid (IAA) metabolism during alcoholic fermentation with four commercial yeast strains (Uvaferm CEG, Lalvin Cross Evolution, Anchor VIN 13 and Anchor exotic SPH) were examined. AS addition reduced Trp uptake by yeasts from $1 \%$ to $15 \%$. Wines produced by Anchor VIN 13 and Uvaferm CEG yeasts with AS addition had the highest concentrations of Trp (0.60 and $0.59 \mathrm{mg} / \mathrm{L}$ respectively). Concentrations of total and bound IAA decreased during all treatments. At the end of fermentation the highest concentration of free IAA was measured in the control must inoculated with Anchor VIN 13 yeast $(35.83 \mu \mathrm{g} / \mathrm{L})$ and the lowest in the sample inoculated with Uvaferm CEG yeast $(13.08 \mu \mathrm{g} / \mathrm{L})$. Anchor VIN 13 yeast showed the strongest change in metabolism due to AS addition during fermentation. 2-Aminoacetophenone (2-AAP) formation was not observed in all the studied wines.
\end{abstract}

\section{INTRODUCTION}

Tryptophan (Trp) and its metabolite, indole-3-acetic acid (IAA), are considered to be potential precursors of 2-aminoacetophenone (2-AAP), an aroma compound that is responsible for "untypical ageing off-flavour" (UTA) in wines (Christoph et al., 1996). UTA can develop in young white wines from Vitis vinifera grapes within a few months after the end of fermentation (Schmarr et al., 2007). UTA off-flavour is described by sensory attributes such as "acacia blossom", "naphthalene", "furniture polish", "fusel alcohol”, "damp cloth" or "hybrid tone" (Fischer \& Sponholz, 2000). The volatile compound 2-AAP is responsible for UTA odour and can be realised organoleptically in wine at 0.5 to 1.5 $\mu \mathrm{g} / \mathrm{L}$ (Christoph et al., 1995). The study of Christoph et al. (1998) on the mechanism of 2-AAP formation showed that 2-AAP can be formed by an oxidative degradation of IAA, which is triggered by a sulphuration of the young wine. However, only unbound IAA is susceptible to this oxidative degradation, while no significant formation of 2-AAP was observed for the ester- or amide-conjugated IAA (Hoenicke et al., 2002). In grape must, more than $95 \%$ of the total IAA is in the bound form, conjugated mainly to amino acids (Hoenicke et al., 2001). Grape must also contains very low amounts of unbound IAA $(<3 \mu \mathrm{g} / \mathrm{L})$. The amount of unbound IAA increases significantly during fermentation, resulting in higher amounts of unbound IAA in the wine $(<3$ to $90 \mu \mathrm{g} / \mathrm{L})$ (Hoenicke et al., 2001). Grape must contains 2 to $80 \mathrm{mg} / \mathrm{L}$ Trp, whereas wine contains $<0.012$ to $24 \mathrm{mg} / \mathrm{L}$ (Hoenicke et al., 2001). During fermentation, the level of Trp decreases because of consumption by the yeast, to a level of between 60 and 100\% (Grossweiner, 1984). In the study of Simat et al. (2004), commercial yeast strains were used at more than $95 \%$ of the initial amount of Trp, indicating its efficient utilisation for the production of biomass (structural proteins and functional enzymes). According to Maslov et al. (2011), the metabolism of Trp and IAA formation during fermentation correlate with the yeast strain. IAA can be released by Saccharomyces yeast through the Trp deamination pathway (Shin et al., 1991). In previous experiments, different oenological parameters were used to modify yeast metabolism. Ammonium supplementation of chemically defined medium resembling the composition of grape juice delayed and reduced the uptake of most amino acids, including Trp (Jiranek et al., 1995). Ružić and Puškaš (2001) showed that the addition of $0.3 \mathrm{~g} / \mathrm{L}$ ammonium sulphate to grape must had an impact on yeast metabolism and tryptophan uptake during fermentation.

The aim of this study was to determine the influence of different commercial yeast strains and ammonium sulphate addition on the metabolism of Trp and free and bound IAA during fermentation, and also on the amount of 2-AAP formed during the storage of the corresponding wines. It could be expected that the addition of ammonium sulphate to must would modify the uptake of precursors by yeast and hence that the wine would have a lower potential for 2-AAP formation. 


\section{MATERIALS AND METHODS}

Samples and fermentation

In 2010, grapes of the Riesling (Vitis vinifera L.) variety were produced and vinificated at the experimental vineyard and cellar of the Faculty of Agriculture in Zagreb. The grapes underwent a vinification procedure for white wines (destemming, crushing and pressing). After that, the grape juice was put in a stainless steel tank for settling for $24 \mathrm{~h}$. Free $\mathrm{SO}_{2}$ was adjusted to $50 \mathrm{mg} / \mathrm{L}$. Clear grape juice was separated in $10 \mathrm{~L}$ glass bottles. Each juice sample was inoculated with an individual yeast strain to the level of $5 \times 10^{6}$ cells $/ \mathrm{mL}$. Four different commercial yeast strains were used. Every yeast strain inoculum was performed without and without the addition of ammonium sulphate $(0.3 \mathrm{~g} / \mathrm{L})$ according to Ružić and Puškaš (2001). All treatments were carried out in triplicate. Fermentations were carried out in a controlled environment at $15{ }^{\circ} \mathrm{C}$. After fermentation the samples were racked from the lees and sulphurised. Free $\mathrm{SO}_{2}$ in the young wines was adjusted to $50 \mathrm{mg} / \mathrm{L}$ and the wines were stored at $15^{\circ} \mathrm{C}$ in the wine cellar. Samples for Trp and IAA were taken at the following four stages: must, beginning of fermentation (24 $\mathrm{h}$ after inoculation), middle of fermentation $(50 \%$ of initial sugar concentration), and end of fermentation. 2-AAP was analysed in the wines after two months of storage in the cellar at $15^{\circ} \mathrm{C}$.

\section{Yeast strains}

Four different commercial yeast strains were tested: Saccharomyces cerevisiae cv. Uvaferm CEG, intraspecific hybrids Saccharomyces cerevisiae cv. Lalvin Cross Evolution and Saccharomyces cerevisiae cv. Anchor VIN 13, and interspecific hybrid Saccharomyces cerevisiae X Saccharomyces paradoxus cv. Anchor Exotics SPH.

Strain Uvaferm CEG is recommended and commonly used for Riesling must fermentation. Other strains were selected according to different nitrogen needs in fermentation (Lallemand yeast catalogue; Oenobrandswww. lallemandwine.com; www.oenobrands.com). All strains were rehydrated in distilled water at $38{ }^{\circ} \mathrm{C}$ and left to stand for 20 minutes before inoculation of the must.

\section{Chemicals}

Indole-3-acetic acid, indole-3-propionic acid and potassium dihydrogen phosphate were purchased from Fluka(Germany). Tryptophan, o-phthaldialdehyde and N-acetyl-L-cysteine reagent were obtained from Sigma (Steinheim, Germany). Methanol (HPLC grade) was purchased from Mallinckrodt J. T. Baker (Deventer, Holland). All other chemicals (p.a. purity) were obtained from Kemika (Zagreb, Croatia). AccuBOND II ENV PS DVB cartridges (1 $000 \mathrm{mg} / 6 \mathrm{~mL}$ ) were from Agilent Technologies (USA). The vacuum manifold was obtained from Agilent Technologies, USA.

\section{Chemical analysis}

Basic chemical analyses of the must and wine were done using methods proposed by the O.I.V. (2007). Free $\alpha$-amino nitrogen (FAN) was measured by a Jena spectrophotometer (Germany), SPECORD 400, according to Dukes and Butzke (1998).

\section{Determination of IAA, Trp and 2-AAP}

The determination of IAA and Trp was performed using HPLC Agilent 1100 equipped with an autosampler and fluorescence detector according to Maslov et al. (2011). 2-Aminoacetophenone was determined by direct immersion (DI) solid phase microextraction (SPME) coupled with Agilent 6890 gas chromatograph (GC) mass spectrometry (MS) using an Agilent 5973N mass detector according to Fan et al. (2007).

\section{Statistical analysis}

A factorial analysis of variance (ANOVA) and Tukey's HSD comparison test were used to interpret statistical differences in means, if any, at the $p<0.05$ confidence level. All statistical analyses was performed using SAS 9.3 software (SAS Institute, Cary, NC, USA).

\section{RESULTS AND DISCUSSION}

\section{General parameters and fermentation}

Low free amino nitrogen (FAN) was measured in the experimental must (Table 1) and was at the lower limit according to the data in the literature. The minimum requirement of free amino nitrogen is reported to be between 70 and $140 \mathrm{mg} / \mathrm{L}$ for the complete fermentation of must with an initial sugar concentration of between 183 and $258 \mathrm{~g} / \mathrm{L}$ (Agenbach, 1977). Yeast strains Uvaferm CEG and Anchor Exotics SPH have average needs for FAN, and Lalvin Cross Evolution and Anchor VIN 13 have lower needs for FAN supply (www.lallemandwine.com; www.oenobrands.com). In Fig. 1 it can be seen that the addition of ammonium sulphate accelerated the fermentation of each yeast strain. The fermentation progression was highest in the must supplemented with ammonium sulphate and inoculated with strains Lalvin Cross Evolution and Anchor VIN 13.

\section{Tryptophan utilisation}

Bisson (1991) reported that amino acids present in low concentrations, like tryptophan (Trp), generally are utilised early in the fermentation. This utilisation mechanism was shown in fermentations carried out by Lalvin Cross Evolution and Anchor VIN 13 yeasts, where Trp was utilised at the start of fermentation (Fig. 2A). This is in agreement with Bisson (1991), who found that amino acids originally present in low concentrations, such as Trp in our case $(2,41 \mathrm{mg} / \mathrm{L})$, were consumed prior to the onset of the growth phase. Jiranek et al. (1995) also reported 50\% depletion of Trp within 24 $\mathrm{h}$ of inoculation and within $25 \mathrm{~h}$ in medium supplemented with ammonium. Differences in Trp consumption intensity between control and AS-supplemented musts were noticed

TABLE 1

Chemical composition of Riesling grape juice

\begin{tabular}{ll}
\hline Compounds & Value \\
\hline Sugar $\left({ }^{\circ} \mathrm{Oe}\right)$ & 92 \\
$\mathrm{pH}$ & 3.1 \\
Total acidity $(\mathrm{g} / \mathrm{L})$ & 9.15 \\
FAN $(\mathrm{mg} \mathrm{N} / \mathrm{L})$ & 75.15 \\
$\operatorname{Trp}(\mathrm{mg} / \mathrm{L})$ & 2.41 \\
\hline
\end{tabular}


only by Lalvin Cross Evolution yeast. This yeast utilised more Trp in the control must compared to in ammoniumsupplemented must $(p<0.05)$. At this point of fermentation,
Anchor Exotics SPH and Uvaferm CEG showed almost no utilisation activity. However, the start of fermentation pointed out significant differences in Trp consumption between

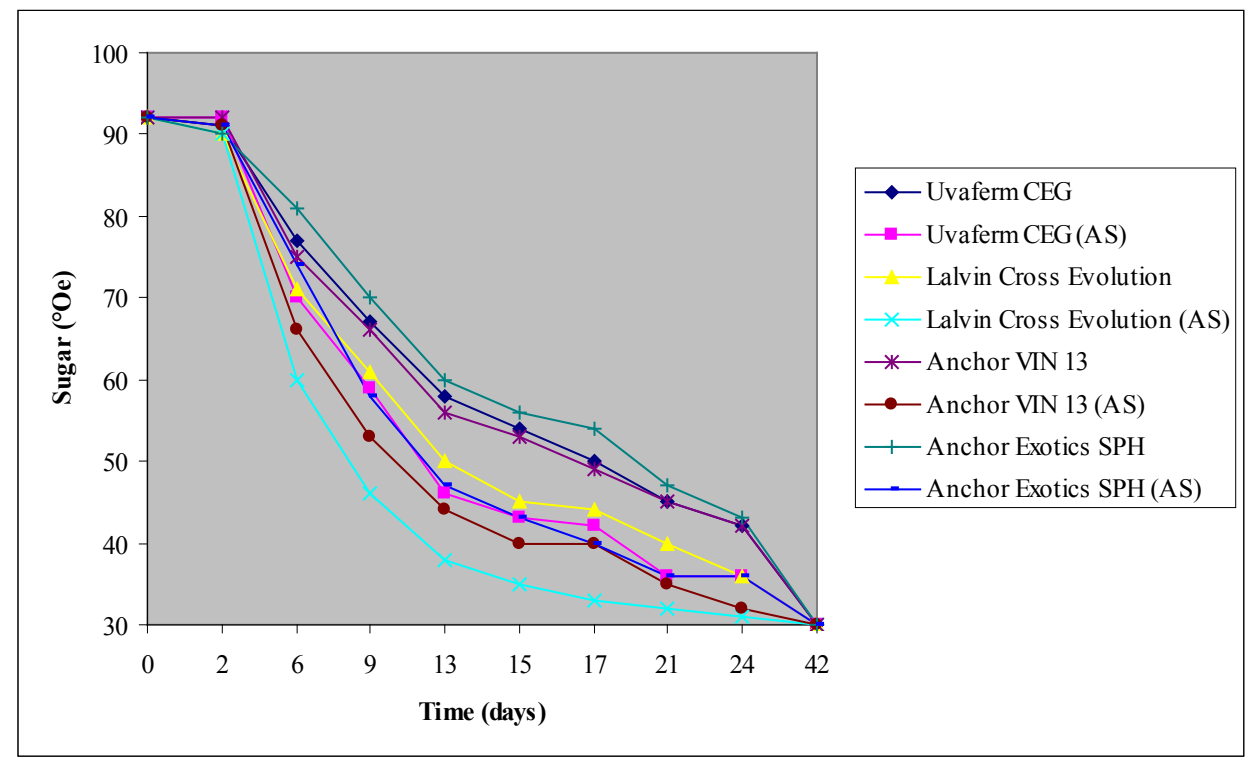

FIGURE 1

Depletion of sugar $\left({ }^{\circ} \mathrm{Oe}\right)$ during fermentation by different yeast strains with and without ammonium sulphate (AS) addition.

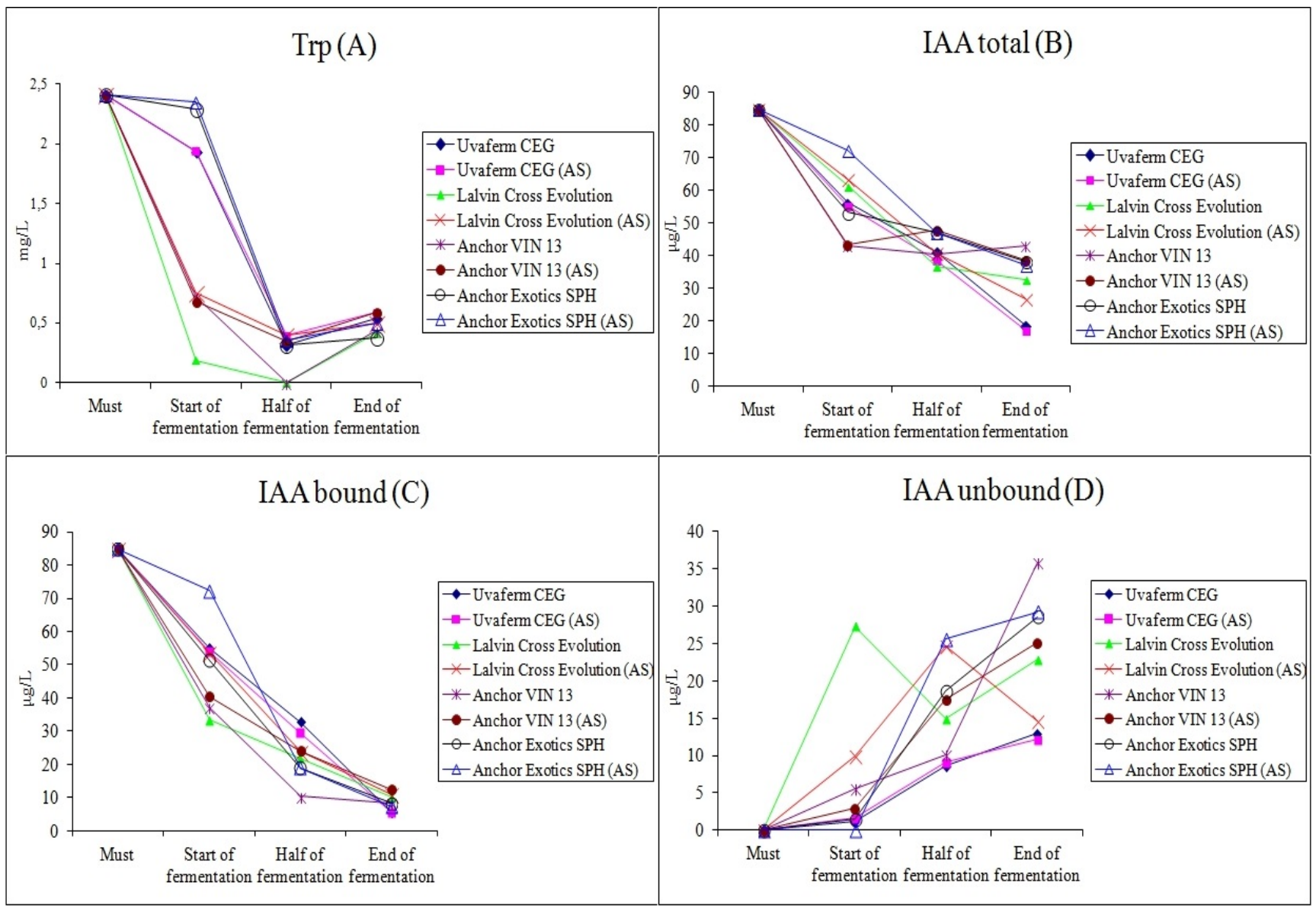

FIGURE 2

Influence of ammonium sulphate (AS) addition on the metabolism of different yeast strains during fermentation. Consumption of Trp (A); trend of total IAA (B); trend of bound IAA (C); trend of unbound IAA (D). Reported values are the means of three determinations. 
all yeast strains tested $(p<0.05)$ (Fig. 3A1). As shown in Fig. 2A, almost all of the Trp present in must was utilised halfway into the fermentation, ranging from traces to 0.32 $\mathrm{mg} / \mathrm{L}$ in control fermentations and 0.35 to $0.40 \mathrm{mg} / \mathrm{L}$ in ASsupplemented musts. This can be connected to the yeast's need for biomass production (Simat et al., 2004). At this point the strongest response to ammonium addition was noticed in fermentations carried out by Anchor VIN 13 and Lalvin Cross Evolution yeasts $(p<0.05)$ (Fig. 3B1). The other two yeasts tested showed small differences in Trp consumption between the control and AS-supplemented musts. Hoenicke et al. (2001) found that the utilisation of Trp by the yeast is dependent on the initial Trp amount in grape juice. If the Trp content of the must is low, nearly $100 \%$ can be utilised, which is confirmed by our results. Accordingly, Trp uptake ranged from 84 to $86 \%$ by Uvaferm CEG and Anchor Exotics SPH yeasts, and $100 \%$ by Lalvin Cross Evolution and Anchor VIN 13 yeasts in the control musts. In musts with AS addition, utilisation by the yeast ranged from $83 \%$ in fermentations by Uvaferm CEG and Lalvin Cross Evolution yeasts, and 85\%

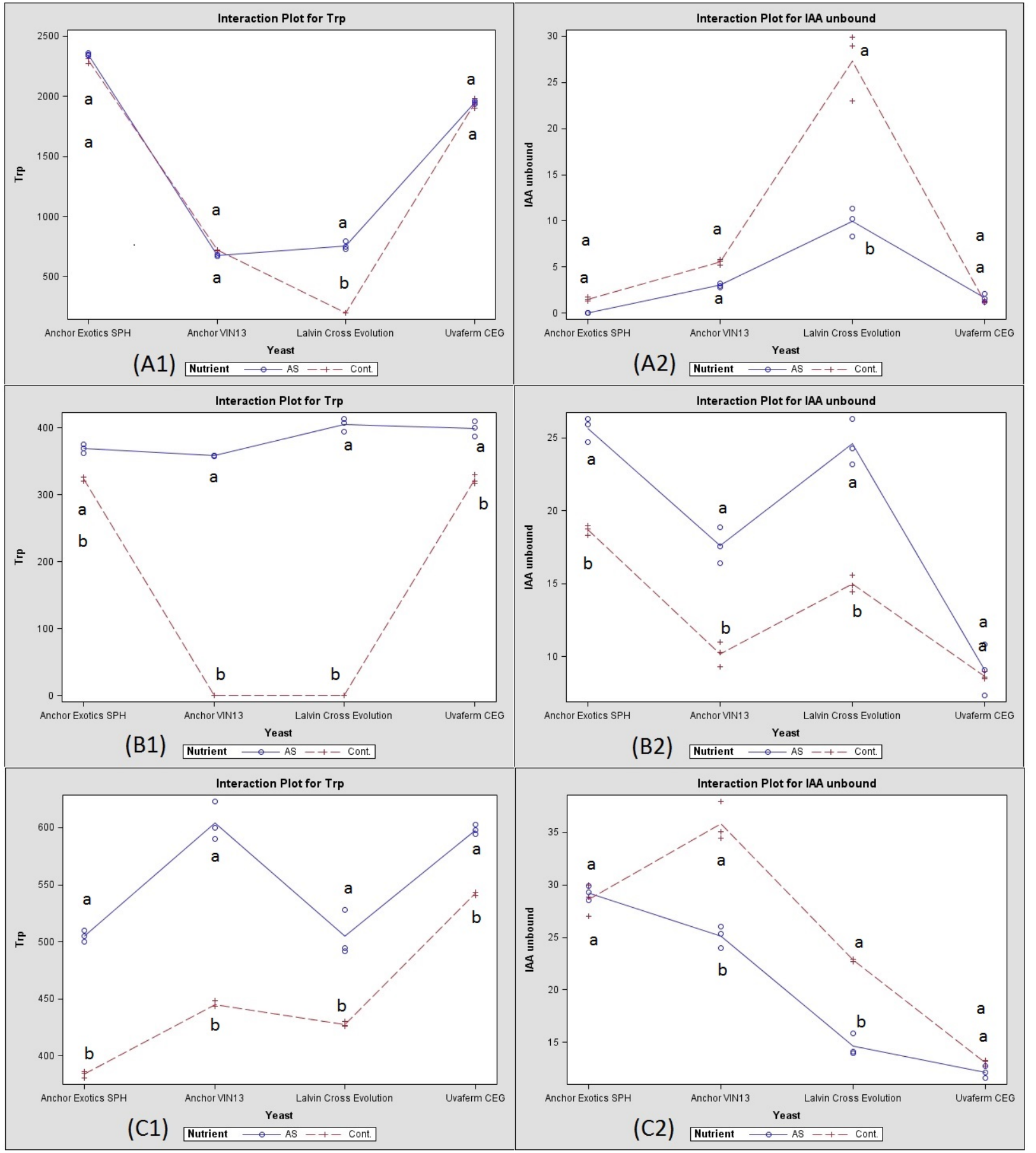

FIGURE 3

Interaction plots for $\operatorname{Trp}(\mu \mathrm{g} / \mathrm{L})$ and unbound IAA $(\mu \mathrm{g} / \mathrm{L})$ at different stages of fermentation: (A1, A2) start of fermentation; (B1, B2) halfway through fermentation; $(\mathrm{C} 1, \mathrm{C} 2)$ end of fermentation; different letters indicate statistical differences within same yeast strain (Tukey's test, $p<0.05$ ). 
in fermentations by Anchor VIN 13 and Anchor Exotics SPH yeasts. At the end of fermentation, the Trp content in all the wines produced increased. The liberation of amino acids at the end of fermentation has already been reported and is a result of yeast autolysis (Monteiro \& Bisson, 1991).

As shown in Fig. 3C1, the control wines produced with Uvaferm CEG yeast had the highest concentration of Trp $(0.54 \mathrm{mg} / \mathrm{L})$, while the lowest concentration was detected in wine produced with Anchor Exotics SPH yeast $(0.38 \mathrm{mg} / \mathrm{L})$. In wines with AS addition, the Anchor VIN 13 and Uvaferm CEG strains had a higher concentration of Trp ( 0.60 and 0.59 $\mathrm{mg} / \mathrm{L}$ ) compared to the Anchor Exotics SPH and Lalvin Cross Evolution yeasts tested $(0.50 \mathrm{mg} / \mathrm{L})$. The strongest influence of ammonium addition was observed with Anchor VIN 13 yeast. Also, differences for all yeasts used were established at the $95 \%$ confidence level using the Tukey HSD test for means. Generally, the consumption of Trp was higher in musts in which ammonium sulphate (AS) was not added by all yeast strains at all points of fermentation $(p<0.05)$. The same behaviour was shown in an experiment by Ružić and Puškaš (2001). Interaction between yeast and nutrient addition was evident in fermentations carried out by Anchor VIN 13 and Lalvin Cross Evolution yeasts.

\section{Metabolism of indole-3-acetic acid}

Only traces of unbound IAA were detected in the must (Fig. 2D). Simat et al. (2004) have found that this might be due to a regulation of this phytohormone by the $V$. vinifera plant. Concentrations of unbound IAA increased during fermentation in all treatments, indicating either a neosynthesis by the yeasts or hydrolysis of bound IAA. At the beginning of fermentation, considerable liberation of unbound IAA was observed in the control and ASsupplemented wines fermented by Lalvin Cross Evolution yeast, while comparable levels of IAA liberation were observed in the other yeasts tested (Fig. 3A2). A decrease in bound IAA was highest within $24 \mathrm{~h}$ after inoculation in all treatments, except in AS-supplemented wines fermented with Anchor Exotics SPH yeast, which reacted to ammonium addition with a delay, similar to Trp uptake (Fig. 2A). The decrease in bound IAA within $24 \mathrm{~h}$ of inoculation was parallel to the Trp uptake. This can be explained by yeast utilisation of bound IAA. Since IAA in the musts is bound to amino acids or peptides, it could be actively transported into the yeast cell, where yeast can utilise the amino acid after hydrolysis (Simat et al., 2004).

A specific transport system in Saccharomyces cerevisiae allows di- and tripeptides to be taken up without prior hydrolysis (Becker \& Naider, 1980). More bound IAA was utilised in control musts with nitrogen deficiency within $24 \mathrm{~h}$ of inoculation. Only strain Uvaferm CEG was not significantly different, in spite of ammonium addition $(p<0.05)$. Since strains Lalvin Cross Evolution and Anchor VIN 13 have lower needs for nitrogen in must, this higher drop in bound IAA during first $24 \mathrm{~h}$ after inoculation in the control must suggests that these strains use other nitrogen sources efficiently. Halfway through fermentation, the concentrations of total IAA and bound IAA continued to decrease (Fig. 2B, C), while unbound IAA concentrations increased (Fig. 2D), which is in agreement with previously published data (Hoenicke et al., 2001; Simat et al., 2004). An exception was noticed in the fermentations performed by Lalvin Cross Evolution yeast, where a marked decrease occurred in unbound IAA. At this stage of fermentation, a significant difference in IAA concentrations was shown between the control musts and ammonium addition musts, with the exception being both Uvaferm CEG yeast treatments, where no difference was detected $(p<0.05)$. Finally, at the end of fermentation (Fig. 3C2) it can be seen that the control must inoculated with Anchor VIN 13 yeast reached the maximum amount of $35.83 \mu \mathrm{g} / \mathrm{L}$ unbound IAA, with the highest increase from halfway through fermentation until the end of fermentation. In contrast, wines fermented with Uvaferm CEG yeast had a minimum concentration of 13.08 $\mu \mathrm{g} / \mathrm{L}$ unbound IAA, and there was no difference between the control and ammonium addition treatments. At the end of fermentation in the ammonium-supplemented must, the highest concentration of unbound IAA was observed in wines fermented by Anchor Exotics SPH yeast (29.24 $\mu \mathrm{g} / \mathrm{L})$, and the lowest in Uvaferm CEG wines $(12.16 \mu \mathrm{g} / \mathrm{L})$. The lowest concentrations of unbound IAA in wines fermented with Uvaferm CEG yeast independently of ammonium supplementation can be correlated with the highest Trp concentration. In Figure 3C2 it can be seen that Anchor VIN 13 and Lalvin Cross Evolution yeasts showed significant reactions on ammonium addition $(p<0.05)$. An increase in unbound IAA in musts inoculated with Anchor VIN 13 yeast halfway through fermentation (control must) and at the start of fermentation (AS-supplemented must) indicates biosynthesis and secretion of unbound IAA by this yeast.

A rapid increase in the concentration of unbound IAA in samples inoculated with Lalvin Cross Evolution yeast is in correlation with Trp consumption and the decrease in bound IAA. This can be related to the Trp deamination pathway of yeast and the synthesis of IAA (Shin et al., 1991). The strongest response to ammonium sulphate addition in must during fermentation was noted in the yeast strains Anchor VIN 13 and Lalvin Cross Evolution.

Bound IAA concentrations dropped from an initial 84.82 $\mu \mathrm{g} / \mathrm{L}$ in the must to minimum concentrations of $5.33 \mu \mathrm{g} / \mathrm{L}$ and $5.48 \mu \mathrm{g} / \mathrm{L}$ in wines fermented with Uvaferm CEG yeast in the control must and supplemented must. At the end of fermentation, a significant difference was observed only in Anchor VIN 13 wines, which ended with the highest bound IAA concentration in ammonium-supplemented treatment $(12.37 \mu \mathrm{g} / \mathrm{L})$ compared to the control $(9.19 \mu \mathrm{g} / \mathrm{L})$ at $p<0.05$.

\section{2-AAP analysis}

Christoph et al. (1998) have shown that the mechanism of 2-AAP can be influenced by an oxidative degradation of IAA, which is triggered by a sulphuration of the young wine. Because of this we stored our sulphurised young wines for two months at a constant temperature of $15^{\circ} \mathrm{C}$. 2-AAP was analysed in 24 samples of wine, but no significant amount of this compound was present. It can be noticed that a relatively high amount of unbound IAA $(35.83 \mu \mathrm{g} / \mathrm{L})$ in wines fermented with Anchor VIN 13 also had no influence on 2-AAP formation. According to Simat et al. (2004), the formation of 2-AAP depends on the storage temperature. A significant increase in 2-AAP was observed when wines 
were stored on $40{ }^{\circ} \mathrm{C}$ for $72 \mathrm{~h}$. Our wines were stored at $15^{\circ} \mathrm{C}$, which could be one of explanations why 2-AAP was not formed.

\section{CONCLUSIONS}

The results of this study show the influence of the commercial yeasts strains used and ammonium sulphate addition $(0.3$ $\mathrm{g} / \mathrm{L}$ ) on the consumption rate and final concentrations of Trp and unbound IAA. A significant increase in unbound IAA concentrations and a decrease in Trp, total and bound IAA concentrations during fermentation were observed in all treatments. Trp was almost completely consumed by all yeast strains by halfway through the fermentation. Ammonium sulphate addition reduced Trp uptake by the yeasts. At the end of fermentation the Trp content increased again, but differences were noticed between yeast strains. The influence of ammonium sulphate addition on Trp uptake and unbound IAA release was notable for the Anchor VIN 13 and Lalvin Cross Evolution yeast strains. In contrast, the response to ammonium sulphate addition by Uvaferm CEG yeast was negligible, showing no differences in Trp and IAA concentrations in the produced wines. According to the results of our study it can be stated that yeast strain Uvaferm CEG can be used in nitrogen-deficient musts in order to reduce the potential precursor of UTA, since it released the lowest concentrations of unbound IAA at the end of fermentation, whereas the use of yeast strain Anchor VIN 13 in nitrogen-deficient musts can enhance IAA concentrations. After two months of storage, 2-AAP formation was not observed in all the analysed wines. Neither yeast strain, nor ammonium sulphate addition, influenced 2-AAP formation. Further work using different combinations of yeast, nutrient and grape varieties is required to confirm this result.

\section{LITERATURE CITED}

Agenbach, W.A., 1977. A study of must nitrogen content in relation to incomplete fermentations, yeast production and fermentation activity. In: Beukman, E.F. (ed). Proc. S.A. Soc. Enol. Vitic., November 1977, Stellenbosch, South Africa. pp. $66-88$.

Becker, J.M. \& Naider, F., 1980. Transport and utilization of peptides by yeast. In: Payne, J.W. (ed.). Microorganisms and nitrogen sources. Wiley, Chichester. pp. $257-279$.

Bisson, L.F., 1991. Influences of nitrogen on yeast and fermentation of grapes. In: Rautz, J.M. (ed). Proc. Intern. Symp. on Nitrogen in Grapes and Wine, June 1991, Seattle, WA, USA. pp. $78-89$.

Christoph, N., Bauer-Christoph, C., Gessner, M. \& Köhler, H.J., 1995. Die "Untypische Alterungsnote" im Wein, Teil I: Untersuchungen zum Auftreten und zur sensorischen Charakterisierung der "Untypischen Alterungsnote". Rebe \& Wein 48, 350-356.

Christoph, N., Bauer-Christoph, C., Gessner, M. \& Köhler, H.J., 1996. Die "Untypische Alterungsnote" im Wein, Teil VI: Untersuchungen zur Bildung von o-Aminoacetophenon aus Produkten des Tryptophan-Stoffwechsels vor der alkoholischen Gärung. Rebe \& Wein 49, 246-250.
Christoph, N., Bauer-Christoph, C., Gessner, M., Köhler, H.J., Simat, T.J. \& Hoenicke, K., 1998. Bildung von 2-aminoacetophenon und formylaminoacetophenon im Wein durch Einwirkung von schwefeliger Säure auf indol-3-essigsäure. Vitic. Enol. Sci. 53, 79-86.

Dukes, B.C. \& Butzke, C.E., 1998. Rapid determination of primary amino acids in grape juice using an $o$-phthaldialdehyde/N-acetyl-L-cysteine spectrophotometric assay. J. Enol. Vitic. 49, 125-134.

Fan, W., Tsai, I.-M. \& Qian, M.C., 2007. Analysis of 2-aminoacetophenone by direct-immersion solid-phase microextraction and gas chromatographymass spectrometry and its sensory impact in Chardonnay and Pinot gris wines. Food Chem. 105, 1144-1150.

Fischer, U. \& Sponholz, W.R., 2000. Die sensorische Beschreibung der Untypischen Alterungsnote. Der Deutsche Weinbau 3, 16-21.

Grossweiner, L., 1984. Phytochemistry of proteins. Curr. Eye Res. 3, 137 144

Hoenicke, K., Simat, T.J., Steinhart, H., Köhler, H.J. \& Schwab, A., 2001. Determination of unbound and conjugated indole-3-acetic acid, tryptophan, and tryptophan metabolites in grape must and wine. J. Agric. Food Chem. 49, 5494-5501.

Hoenicke, K., Simat, T.J., Steinhart, H., Christoph, N., Geßner, M. \& Köhler, H.J., 2002. 'Untypical ageing off-flavor' in wine: Formation of 2-aminoacetophenone and evaluation of its influencing factors. Anal. Chim. Acta 485, 29-37.

Jiranek, V., Langridge, P. \& Henschke, P.A., 1995. Amino acid and ammonium utilization by Saccharomyces cerevisiae wine yeasts from a chemically defined medium. Am. J. Enol. Vitic. 46, 75-83.

Lallemand yeast catalogue, n.d. Available: http://www.lallemandwine.com (Accessed 06 February 2014).

Maslov, L., Jeromel, A., Herjavec, S., Jagatić Korenika, A., Mihaljević, M. \& Plavša, T., 2011. Indole-3-acetic acid and tryptophan in Istrian Malvasia grapes and wine. J. Food Agric. Environ. 9, 132-136.

Mattivi, F., Vrhovšek, U. \& Versini, G., 1999. Determination of indole3 -acetic acid, tryptophan and other indoles in must and wine by highperformance liquid chromatography with fluorescence detection. J. Chromat. A 855, 227-235.

Monteiro, F.F. \& Bisson, L.F., 1991. Amino acid utilization and urea formation during vinification fermentations. Am. J. Enol. Vitic. 42, 199-208.

Oenobrands, n.d. Products, Yeasts. Available: http://www.oenobrands.com (Accessed 06 February 2014).

O.I.V. 2007. Compendium of international methods of wine and must analysis. Vol. 1. Paris: O.I.V.

Ružić, E.N. \& Puškaš, V.S., 2001. Effect of $\left(\mathrm{NH}_{4}\right)_{2} \mathrm{SO}_{4}$ addition to grape must on tryptophan content in wine. Rom. Biotechnol. Letts 6, 389-395.

Schmarr, H.G., Ganß, S., Sang, W. \& Potouridis, T., 2007. Analysis of 2-aminoacetophenone in wine using a stable isotope dilution assay and multidimensional gas chromatography-mass spectrometry. J. Chromat. A $1150,78-84$.

Shin, M., Shinguu, T., Sano, K. \& Umezawa, C., 1991. Metabolic fates of L-tryptophan in Saccharomyces uvarum (Saccharomyces carlsbergensis). Chem. Pharmaceut. Bulletin 39, 1792-1795.

Simat, T.J., Hoenicke, K., Gessner, M. \& Christoph, N., 2004. Metabolism of tryptophan and indole-3-acetic acid formation during vinification and its influence on the formation of 2-aminoacetophenone. Mitteilungen Klosterneuburg 54, 43-55. 